\title{
Role of second transurethral resection in determining residual tumor in nonmuscle- invasive bladder cancer
}

Pukar Maskey ${ }^{1}$, Pawan Raj Chalise ${ }^{2}$, Uttam Kumar Sharma ${ }^{3}$, Prem Raj Gyawali ${ }^{3}$, Guna Kumar Shrestha ${ }^{4}$, Bhola Raj Joshi ${ }^{5}$

${ }^{1}$ Associate Professor, Department of Surgery, Patan Academy of Health Sciences

${ }^{2}$ Assistant Professor, Department of Urology, Tribhuvan University Teaching Hospital

${ }^{3}$ Professors, Department of Urology, Tribhuvan University Teaching Hospital

${ }^{4}$ Professor, Department of Surgery, Manmohan Memorial Teaching Hospital

${ }^{5}$ Professor, Department of Surgery, Nepal Medical College

Correspondence: Dr Pukar Maskey, Department of Surgery, Patan Hospital, Patan Academy of Health Sciences.

E-mail: pukarmaskey@hotmail.com

\section{Abstract}

Introduction: Presence of residual tumors is not an uncommon event after transurethral resection of bladder tumor, and no studies from Nepal so far has addressed this issue. We conducted this study to determine the rate of residual tumors after first transurethral resection of nonmuscle-invasive bladder cancer, and to determine the factors associated with the presence of residual tumors and upstaging of nonmuscle-invasive bladder cancer.

Methods: This was a prospective observational study of 43 patients of bladder cancer who had a diagnosis of nonmuscle-invasive bladder cancer following an initial transurethral resection. Demographic data and data on tumor characteristics were obtained. Patients underwent a second transurethral resection within 2 to 8 weeks. Histopathological findings at first and second resection were compared.

Results: There were 20 patients with Ta tumor and 23 patiens with T1 tumor at initial resection. Residual tumor was detected in $18(41.86 \%)$ patients overall, 2 in patients with Ta tumor $(10 \%)$ and 16 in patients with T1 tumor (69.5\%). Tumors with T1 stage, high grade, size more than 3 centimeters and sessile growth pattern were seen to have significant association with the presence of residual tumors. Six patients with T1 disease upstaged to T2 disease after second resection (26\%), while there were no upstaging with Ta tumors. Tumors with T1 stage, sessile configuration and size more than 3 centimeters were found to be significantly associated with upstaging.

Conclusion: A second transurethral resection for nonmuscle-invasive bladder cancer should be considered if the initial tumor is T1 stage, high grade, more than 3 centimeters in size and has sessile growth pattern.

Key words: Nonmuscle invasive bladder tumor; Second TURBT; TURBT. 


\section{Introduction}

Approximately $70 \%$ of urothelial bladder cancers are non-muscle invasive bladder cancers (NMIBC) at initial presentation. ${ }^{1}$ A transurethral resection of bladder tumor (TURBT) and adjuvant intravesical therapy is the standard initial treatment for this condition. Unfortunately, the disease recurs in $70 \%$, and progresses in $10 \%-30 \%$ after initial treatment. ${ }^{2}$ The initial TURBT might also not adequately stage the disease, and the rate of residual disease after initial TURBT ranges from $20 \%$ to $78 \%{ }^{3}$ Understaging after initial TURBT is common, as one series of radical cystectomy for NMIBC showed that upto $40 \%$ were clinically understaged, and upto $80 \%$ of these were cT1 based on initial TURBT. ${ }^{4}$ An important reason for these is an inadequate initial resection, which is indicated by an absence of detrusor muscle in the resected specimen.

A second TURBT (also known as reTURBT or restaging TURBT) is done 2-6 weeks after the initial TURBT. ${ }^{5}$ It aims to adequately stage the disease and to eliminate residual disease. It confers added benefits of recurrence free survival and delay in progression, and a better shortterm response to BCG therapy. ${ }^{6,7,8}$

Till date, no published studies from Nepal have assessed the role of restaging TUR in the management of NMIBC. Hence the current study was done to assess the rate of detection of residual tumor following an initial TURBT, and to assess the factors associated with the presence of residual tumors and tumor upstaging.

\section{Methods}

This was a prospective observational study conducted in the urology unit, department of surgery, TUTH. Written informed consent was obtained from all patients, and approval was obtained from institutional review board.

The first TURBT was done in lithotomy position under spinal anesthesia. The location, number, size and appearance of the tumor were noted, as was the appearance of surrounding mucosa. Resection was done with 26 Fr continuous-flow active resectoscope by Karl Storz, using the fractionated resection technique. Base of the tumor was resected separately and sent for histopathologic examination. Any suspicious-looking areas were also biopsied. Mitomycin C 40mg was instilled intravesically at the end of the procedure. The second resection was done 2-8 weeks after the first TURBT. All visible tumors, previous resection scar and edematous areas from previous biopsy sites were resected. Both the first and second resections were performed by consultants, and the operating surgeon for the first and second surgery could be the same or different.

Tumors were classified according to the TNM staging system given by AJCC/UICC $7^{\text {th }}$ edition, and graded according to the WHO/ISUP grading system. All patients who had NMIBC in the histopathology report following first TURBT were eligible to undergo second TURBT, and were included in the study. Patients who had a diagnosis of muscle-invasive disease at initial TURBT, and patients with poor performance status (Eastern Cooperative Oncology Group $\geq 3$ ) were excluded from the study.

Residual tumor was defined as presence of tumor at second TURBT (at the same site or different site) after an apparently complete first resection.

Variables taken for analysis after first TURBT were as follows: number of primary tumor, largest size of primary tumor, type of primary tumor (papillary versus sessile), T-stage of primary tumor, grade of primary tumor, and the presence or absence of detrusor muscle in the first resection specimen.

Variables taken for analysis after second TURBT included the number of patients with residual tumors, and the number of patients with upstaged tumors.

Statistical analysis was done using SPSS, version 17. Continuous variables were expressed as mean \pm standard deviation. Chi-square test and Fisher exact test were used to evaluate the association of characteristics of primary tumor with the presence of residual disease and upstaging. $\mathrm{P}$ value $<0.05$ was regarded as significant. The study was conducted for 18 months and the outcome assessor was not blinded.

\section{Results}

Out of 47 patients, 4 patients lost to follow-up, hence second TURBT was done in 43 cases.

The mean age of the patients was $63.77 \pm 11.37$ years, and the patients were predominantly males (female: male 1 : $6.1)$. There were $25(58.14 \%)$ patients with multiple tumors and $18(41.86 \%)$ patients with solitary tumor. Twenty five $(58.14 \%)$ patients had tumors less than 3 centimeters in size, and $18(41.86 \%)$ had tumors $\geq 3$ centimeters. The tumors were papillary in $24(55.81 \%)$, and sessile in 19 (44.18\%). Twenty three $(53.48 \%)$ patients had T1 tumor and $20(46.51 \%)$ had Ta tumor. Of the Ta tumor, 14 (70\%) were low grade and $6(30 \%)$ were high grade. However, 
all T1 tumors were high grade. Overall, 14 patients (32.55\%) had low grade, and $29(67.44 \%)$ had high grade tumors. Detrusor muscle was present in the first resection specimen in $32(74.41 \%)$, and absent in $11(25.58 \%)$ patients.

After second TURBT, residual tumor was found in 18 patients, giving a rate of residual tumor of $41.86 \%$. The residual tumors were found at the site of previous tumor in 13 cases, at new location in 3 cases, and both at the site of previous and new location in 2 cases. (Table 1)

Table 1: Histopathology after after second TURBT

\begin{tabular}{|c|c|c|c|c|c|c|c|c|c|}
\hline $\begin{array}{l}\text { Initial } \\
\text { T-stage }\end{array}$ & $\mathrm{N}=43$ & $\begin{array}{l}\text { T-s } \\
\text { T0 }\end{array}$ & $\begin{array}{c}\text { age a } \\
\text { Ta }\end{array}$ & Tis $2^{n}$ & $\begin{array}{l}\text { TUF } \\
\text { T1 }\end{array}$ & $\begin{array}{l}\text { BT } \\
\text { T2 }\end{array}$ & $\begin{array}{l}\text { Residual Tumor } \\
(\%)\end{array}$ & $\begin{array}{l}\text { Overall } \\
\text { Upstaging } \\
(\%)\end{array}$ & $\begin{array}{l}\text { Upstaging } \\
\text { to } \\
\text { T2 (\%) }\end{array}$ \\
\hline $\mathrm{Ta}$ & 20 & 18 & 1 & 1 & 0 & 0 & $2(10)$ & 0 & 0 \\
\hline $\mathrm{T} 1$ & 23 & 7 & 2 & 1 & 7 & 6 & $16(69.5)$ & $6(26.08)$ & $6(26.08)$ \\
\hline
\end{tabular}

Considering both Ta and T1 initial stages, the overall rate of upstaging was $13.95 \%$.

Of the 6 tumor-related variables studied, only the following factors were seen to have a significant association with the presence of residual tumors at second resection: tumor size more than 3 centimeters, sessile growth pattern, T1 stage and high grade. (Table 2)

Table 2: Association between primary tumor characteristics and presence of residual tumors

\begin{tabular}{|c|c|c|c|c|}
\hline Variables & $N=43$ & Residual tumor & $\chi^{2}$ & $p$ value \\
\hline \multicolumn{5}{|c|}{ Number of tumor } \\
\hline Single & 18 & 7 & \multirow{3}{*}{0.112} & \multirow{2}{*}{0.738} \\
\hline Multiple & 25 & 11 & & \\
\hline \multicolumn{4}{|l|}{ Size } & \\
\hline$<3 \mathrm{cms}$ & 25 & 6 & \multirow[b]{2}{*}{7.828} & \multirow[b]{2}{*}{0.011} \\
\hline$\geq 3 \mathrm{cms}$ & 18 & 12 & & \\
\hline \multicolumn{5}{|l|}{ Type } \\
\hline Papillary & 24 & 3 & \multirow{2}{*}{19.239} & \multirow{2}{*}{0.001} \\
\hline Sessile & 19 & 15 & & \\
\hline \multicolumn{5}{|l|}{ Grade } \\
\hline Low & 14 & 1 & \multirow[b]{2}{*}{10.281} & \multirow[b]{2}{*}{0.001} \\
\hline $\begin{array}{l}\text { High } \\
\text { Stage }\end{array}$ & 29 & 17 & & \\
\hline $\mathrm{Ta}$ & 20 & 2 & \multirow{2}{*}{15.595} & \multirow{2}{*}{0.001} \\
\hline $\mathrm{T} 1$ & 23 & 16 & & \\
\hline \multicolumn{5}{|c|}{ Detrusor muscle } \\
\hline Present & 32 & 11 & & \multirow[t]{2}{*}{$0.156^{*}$} \\
\hline Absent & 11 & 7 & & \\
\hline
\end{tabular}




\section{$\chi^{2}=$ Pearsons Chi-square value}

\section{* Fisher's Exact test}

All six patients (13.95\%) who had their tumor upstaged (to T2) as a result of second resection, had T1 tumor in the first resection. None of the patients with Ta tumors in the first resection were upstaged. Of the six factors studied, only the following factors were seen to have a significant association with upstaging: size more than 3 centimeters, sessile growth pattern and T1 stage. (Table 3)

Table 3: Association between primary tumor characteristics and upstaging

\begin{tabular}{|c|c|c|c|}
\hline Variables & $\mathbf{N}=\mathbf{4 3}$ & Upstaged to $\mathrm{T} 2$ & $p$ value ${ }^{*}$ \\
\hline Number & & & \multirow{3}{*}{0.067} \\
\hline Single & 18 & 5 & \\
\hline $\begin{array}{l}\text { Multiple } \\
\text { Size }\end{array}$ & 25 & 1 & \\
\hline$<3 \mathrm{cms}$ & 23 & 0 & \multirow[b]{2}{*}{0.003} \\
\hline $\begin{array}{l}\geq 3 \mathrm{cms} \\
\text { Type }\end{array}$ & 18 & 6 & \\
\hline Papillary & 24 & 0 & \multirow{2}{*}{0.004} \\
\hline $\begin{array}{c}\text { Sessile } \\
\text { Stage }\end{array}$ & 19 & 6 & \\
\hline $\mathrm{Ta}$ & 20 & 0 & \multirow{2}{*}{0.023} \\
\hline $\begin{array}{r}\mathrm{T} 1 \\
\text { Grade }\end{array}$ & 23 & 6 & \\
\hline Low & 14 & 0 & \multirow{2}{*}{0.115} \\
\hline High & 29 & 6 & \\
\hline \multicolumn{4}{|c|}{ Detrusor muscle } \\
\hline Present & 32 & 2 & \multirow{2}{*}{0.29} \\
\hline Absent & 11 & 4 & \\
\hline
\end{tabular}

*Fisher Exact test

\section{Discussion}

TURBT is a diagnostic and a therapeutic procedure in that it not only reveals the histological type, stage and grade of bladder tumor, but can also lead to eradication of NMIBC. However, in-spite of an apparently complete initial TUR, $20 \%$ to $78 \%$ of patients will have residual tumors left behind. ${ }^{3}$ Furthermore, $27 \%$ to $78 \%$ of patients are understaged following an initial TURBT. ${ }^{4,9,10,11,12} \mathrm{~A}$ second TURBT not only eradicates residual tumor, but can also correct the staging error of the first TURBT. It is recommended that the second resection be performed within 2 to 6 weeks of the initial resection. ${ }^{5}$ In the current study, patients coming within 8 weeks of resection were included because most of the patients are from remote places. 
In the current study, the rate of residual tumor was $41.86 \%$, and this was related to T1 stage in $37.20 \%$ and to Ta stage in $4.65 \%$. Our data is comparable to most of the previous reports, which also reveal that residual tumor is more common (as high as 78\%) with T1 stage in the first resection. , $^{613,14,15,16,17,18}$ (Table 4)

Table 4: Studies showing rate of residual tumor after second TURBT for Ta and T1

\begin{tabular}{|c|c|c|c|c|}
\hline Study, year & $\begin{array}{l}\text { No. of } \\
\text { patients, Ta }\end{array}$ & $\begin{array}{l}\% \text { residual tumor after } \\
\text { second TURBT }\end{array}$ & $\begin{array}{l}\text { No. of } \\
\text { patients } \mathrm{T} 1\end{array}$ & $\begin{array}{l}\% \text { residual tumor after } \\
\text { second TURBT }\end{array}$ \\
\hline Klan $1991^{13}$ & & & 46 & 20 \\
\hline Herr $1999^{14}$ & 18 & 72 & 58 & 78 \\
\hline Schips $2002^{15}$ & 31 & 39 & 76 & 33 \\
\hline Grimm $2003^{6}$ & 59 & 27 & 19 & 53 \\
\hline $\begin{array}{l}\text { Zukirchen } \\
2004^{16}\end{array}$ & 99 & 27 & 115 & 37 \\
\hline
\end{tabular}

$\begin{array}{lcccc}\text { Han } 2008^{17} & 25 & 64 & 30 & 66.7 \\ \text { Ali } 2010^{18} & 30 & 40 & 61 & 67.2 \\ \text { Current study } & \mathbf{2 0} & \mathbf{1 0} & \mathbf{2 3} & \mathbf{6 9 . 5}\end{array}$

The reason why residual tumors are common after resection of T1 tumors is because once the tumor has invaded the lamina propria, the radicality of TUR cannot be monitored because of limitations in visual identification of tumor. ${ }^{3}$ Furthermore, tumor spreading towards the deep muscle bundles and beneath the urothelium can limit the success of TURBT. Moreover, different patterns of invasion in cases of T1 tumors (broad-front or tentacular invasion) may contribute to the persistence of residual tumor. ${ }^{18}$

This study did not reveal a significant association between Ta stage and presence of residual tumor. In fact, the guidelines and studies do not recommend a second resection for Ta tumors especially if it is low grade and is not large or multiple..$^{5,15}$

However, the studies quoted in table 1 show residual tumor during second resection even for Ta tumors, and some recommend doing a repeat resection even for Ta G1 bladder cancer, especially in patients referred to an academic center, considering the possibility of an inadequately performed resection in the community hospital. ${ }^{17,19}$
In addition to the initial $\mathrm{T}$ stage, the current study has also shown a statistically significant association between sessile growth pattern, size more than 3 centimeters and high grade, and the presence of residual tumors. Similar findings have been reported by other studies as well., ${ }^{6,20}$ These studies also report an association between multiplicity of tumors and presence of residual tumor. The current study, however, did not reveal a statistically significant association between multiple tumors and presence of residual tumors. However, when patients are grouped as those with 1 or 2 tumors, and 3 or more tumors, only $30.76 \%$ of the former group had residual tumor compared to $58.82 \%$ of the latter group. Hence, a trend towards increased presence of residuals with increasing number of tumors can still be seen in this study.

The rate of upstaging of tumor in the current study was $13.95 \%$. All of the upstaging was noted in patients with T1 stage. When considering only $\mathrm{T} 1$ stage patients, the rate of upstaging was $26.08 \%$. Our findings are similar to the findings reported by other series (table 5) where the rate of rate of upstaging has been reported between 7-29\%.,14,15,21,22 
Table 5: Studies on rate of residual tumor and upstaging after second TURBT

\begin{tabular}{|c|c|c|c|c|}
\hline Study, year & No. of patients & T stage at $1^{\text {st }}$ TURBT & Upstaging \% & Residual tumor \% \\
\hline Herr, $1999^{14}$ & 96 & Tis, Ta, T1 & 29 & 75 \\
\hline Schwaibold, $2000^{3}$ & 136 & $\mathrm{~T} 1$ & 21 & 52 \\
\hline Schips, $2002^{15}$ & 110 & $\mathrm{Ta}, \mathrm{T} 1$ & 8 & 18 \\
\hline Dalbagni, $2009^{21}$ & 523 & $\mathrm{~T} 1$ & 20 & \\
\hline Divrik, $2010^{22}$ & 105 & $\mathrm{~T} 1$ & 7 & 33 \\
\hline Current study & 43 & Ta, T1 & $13.95 \%$ & $41.86 \%$ \\
\hline
\end{tabular}

In the current study, upstaging was seen only with T1 tumors. None of the Ta tumors were upstaged. Along with $\mathrm{T} 1$ stage, other factors that were seen to have statistically significant association with upstaging in this study were size more than 3 centimeters and sessile growth pattern, paralleling the findings by Ali et al. ${ }^{18}$

The current study however did not reveal significant association between high grade and absence of detrusor muscle (factors which have been found to be significant in other studies ${ }^{14,18}$ ), and pathological upstaging. T2 tumors are high grade by definition ${ }^{23}$, and all of the $6 \mathrm{~T} 1$ tumors upstaged to T2 in this study were high grade. Absence of detrusor muscle in the initial resection specimen is regarded as one of the most important factors in T1 tumor understaging. ${ }^{5,24}$ In the current study, detrusor muscle was absent in the initial resection specimen in $25.58 \%$ of patients, which is similar to other studies that have shown absence of muscularis propria in $30 \%-50 \%$ of submitted specimens. ${ }^{25,26}$ In this study, though, $36.36 \%$ patients without detrusor muscle versus $6.25 \%$ patients with detrusor muscle in the first resection specimen were upstaged, and $63.63 \%$ patients without detrusor muscle versus $34.37 \%$ patients with detrusor muscle in the first resection specimen had residual tumors. Similarly, this study did not reveal a significant association between multifocality of tumor and upstaging to $\mathrm{T} 2$, similar to study by Ali et al., where nodularity, size $>3$ centimeters, T1 stage and high grade were associated with upstaging to T2, whereas presence of carcinoma-in-situ and number of tumors were not. ${ }^{18}$

This was a time-bound study, and the small sample size precluded a multivariate analysis to assess the relation between tumor variables and the presence of residuals and upstaging. Pre-operative urine cytology findings were not included in the initial evaluation, and different consultants performed the surgeries.

\section{Conclusion}

The rate of residual tumor after first TURBT of NMIBC is observed to be $41.86 \%$. NMIBC with T1 stage, high grade, size more than 3 centimeters and sessile growth pattern are associated with the presence of residual tumor and upstaging in the second transurethral resection. A second TURBT should be considered in patients with these tumor characteristics.

\section{References}

1. Hall MC, Chang SS, Dalbagni G, Pruthi RS, Seigne JD et al. Guideline for the management of nonmuscle invasive bladder cancer (stages Ta, T1 and Tis): 2007 update. J Urol 2007. 178(6):2314-30. https://doi.org/10.1016/j.juro.2007.09.003 PMid:17993339

2. Konety BR, Williams RD. Superficial transitional (Ta/T1/CIS) cell carcinoma of the bladder. BJU Int 2004; 94(1):18-21. h t t p s : / / d o i.org / $10.1111 /$

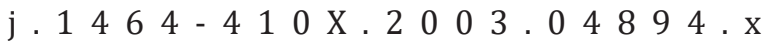
PMid: 15217424

3. Schwaibold HE, Sivalingam S, May F, Hartung R. The value of a second transurethral resection for T1 bladder cancer. BJU Int 2006; 97(6):1199-201. h t t p s : / / d o i . o r g / $10.1111 /$ j. $14644-410$ X. 20006 . 066144 . 6 PMid:16566814 
4. Dutta SC, Smith JA Jr, Shappell SB, Coffey CS, Chang SS et al. Clinical understaging of high risk nonmuscle invasive urothelial carcinoma treated with radical cystectomy. J Urol 2001; 111(2):490-3. https://doi.org/10.1016/S0022-5347(05)659691

5. Babjuk M, Oosterlinck W, Sylvester R, Kaasinen E, Böhle A et al. EAU guidelines on nonmuscle invasive urothelial carcinoma of the bladder, the 2011 update. Eur Urol 2011; 59(6):997-1008. https://doi.org/10.1016/j.eururo.2011.03.017 PMid:21458150

6. Grimm MO, Steinhoff C, Simon X, Spiegelhalder P, Ackermann R et al. Effect of routine repeat transurethral resection for superficial bladder cancer: a long-term observational study. J Urol 2003; 170(2 Pt 1):433-7. h t t p s : / / d o i . org / $10.1097 / 01$. j u. $\begin{array}{lllllllllllllllllllllll}0 & 0 & 0 & 0 & 0 & 7 & 0 & 4 & 3 & 7 & 1 & 4 & 2 & 7 & 5\end{array}$. e 0 PMid:12853793

7. Divrik RT, Yildirim U, Zorlu F, Ozen H. The effect of repeat transurethral resection on recurrence and progressionratesin patients with T1 tumors of the bladder who received intravesical mitomycin: a prospective, randomized clinical trial. J Urol 2006; 175(5):1641-4. https://doi.org/10.1016/S0022-5347(05)010025

8. Herr HW. Restaging transurethral resection of high risk superficial bladder cancer improves the initial response to bacillus CalmetteGuerin therapy. J Urol 2005; 174(6):2134-7. h t t p s : / / d o i . org/10.1097/0 1 . j u . $\begin{array}{lllllllllllllllllll}0 & 0 & 0 & 0 & 1 & 8 & 1 & 7 & 9 & 9 & . & 8 & 1 & 1 & 1 & 9 & \text {. f } & c\end{array}$ PMid:16280743

9. Badalato G, Patel T, Hruby G, McKiernan J. Does the presence ofmuscularis propria on transurethral resection of bladder tumor specimens affect the rate of upstaging in cT1 bladder cancer? BJU Int 2011; 108(8):1292-6. h t t p s : / / d o i.o r g / 10 . 1111 / j. $14664-410$ X. $201010.098993 . x$ PMid:21176080

10. Weizer AZ, Wasco MJ, Wang R, Daignault $\mathrm{S}$, Lee CT et al. Multiple adverse histological features increase the odds of understaging T1 bladder cancer. J Urol 2009; 182(1):59-65. https://doi.org/10.1016/j.juro.2009.02.116 PMid:19447443
11. Gupta A, Lotan Y, Bastian PJ, Palapattu GS, Karakiewicz PI et al. Outcomes of patients with clinical T1 grade 3 urothelial cell bladder carcinoma treated with radical cystectomy. Urology 2008; 71(2):302-7. https://doi.org/10.1016/j.urology.2007.10.041 PMid: 18308108

12.

13. Bianco FJ Jr, Justa D, Grignon DJ, Sakr WA, Pontes JE et al. Management of clinical T1 bladder transitional cell carcinoma by radical cystectomy. Urol Oncol 2004; 22(4):290-4. https://doi.org/10.1016/S1078-1439(03)001443

14. Klan R, Loy V, Huland H. Residual tumor discovered in routine second transurethral resection in patients with stage $\mathrm{T} 1$ transitional cell carcinoma of the bladder. J Urol 1991;146(2):316-8. https://doi.org/10.1016/S0022-5347(17)377790

15. Herr HW. The value of a second transurethral resection in evaluating patients with bladder tumors. J Urol 1999; 162(1):74-6. https://doi.org/10.1097/00005392$\begin{array}{lllllllllllllll}1 & 9 & 9 & 9 & 0 & 7 & 0 & 0 & 0 & - & 0 & 0 & 0 & 1 & 8\end{array}$ PMid:10379743

16. Schips L, Augustin H, Zigeuner RE, Gallé G, Habermann $\mathrm{H}$ et al. Is repeated transurethral resection justified in patients with newly diagnosed superficial bladder cancer? Urology 2002;59(2):220-3. https://doi.org/10.1016/S0090-4295(01)015229

17. Zukirchen MA, Sulser T, Gaspert A, Hauri D. Second transurethral resection of superficial transitional cell carcinoma of the bladder: a must even for experienced urologists. Urol Int 2004; 72(2):99-102. h ttps: / / doi.org/10.1159/000075961 PMid: 14963348

18. HanKS, Joung JY, ChoKS, SeoHK, Chung Jetal. Results of repeated transurethral resection for a second opinion in patients referred for nonmuscle invasive bladder cancer: the referral cancer center experience and review of the literature. J Endourol 2008; 22(12):2699-704. https://doi.org/10.1089/end.2008.0281 PMid:19025393 
19. Ali MH, Ismail IY, Eltobgy A, Gobeish A. Evaluation of second-look transurethral resection in restaging of patients with nonmuscle-invasive bladder cancer. J Endourol 2010; 24(12):2047-50. https: / / doi.org/10.1089/end.2010.0319 PMid:20929433

20. Brausi M, Witjes JA, Lamm D, Persad R, Palou J et al. A review of current guidelines and best practice recommendations for the management of nonmuscle invasive bladder cancer by the International Bladder Cancer Group. J Urol 2011; 186(6):2158-67. https://doi.org/10.1016/j.juro.2011.07.076, PMid:22014799

21. Dwivedi US, Kumar A, Das Sk, Trivedi S, Kumar $M$ et al. Relook TURBT in superficial bladder cancer: its importance and its correlation with the tumor ploidy. Urol Oncol 2009; 27(5):514-9. https://doi.org/10.1016/j.urolonc.2008.04.015, PMid:18639472

22. Dalbagni G, Vora K, Kaag M, Cronin A, Bochner $\mathrm{B}$ et al. Clinical outcome in a contemporary series of restaged patients with clinical T1 bladder cancer. Eur Urol 2009; 56(6):903-10. https://doi.org/10.1016/j.eururo.2009.07.005, PMid:19632765

23. Divrik RT, Sahin AF, Yildirim U, Altok M, Zorlu F et al. Impact of routine second transurethral resection on the long term outcome of patients with newly diagnosed pT1 urothelial carcinoma with respect to recurrence, progression rate and disease-specific survival: a prospective randomized clinical trial. Eur Urol 2010; 58(2):185-90. https://doi.org/10.1016/j. eururo.2010.03.007, PMid:20303646

24. Wein AJ et al. In Campbell-Walsh Urology 2011; Elsevier Health Sciences

25. Kolozsy Z. Histopathological "self control" in transurethral resection of bladder tumors. $\mathrm{Br}$ J Urol 1991; 67(2):162-4. https://doi.org/10.1111/j.1464-410X.1991. tb15100.x, PMid:2004228
26. Mariappan P, Zachou A , Grigor KM. Detrusor muscle in the first, apparently complete transurethral resection of bladder tumour specimen is a surrogate marker of resection quality, predicts risk of early recurrence, and is dependent on operator experience. Eur Urol 2010; 57(5):843-9. https://doi.org/10.1016/j.eururo.2009.05.047, PMid:19524354

27. Maruniak NA, Takezawa K, Murphy WM. Accurate pathological staging of urothelial neoplasms requires better cystoscopic sampling. J Urol 2002; 167(6):2404-7. ht t p s: / / doi.org / 10.1016 / S 0022 5347(05)64993-2 